\title{
Nogo receptor knockdown and ciliary neurotrophic factor attenuate diabetic retinopathy in streptozotocin-induced diabetic rats
}

\author{
XILIANG GUO $^{1,2}$ and XUEZHENG LIU ${ }^{1,2}$ \\ ${ }^{1}$ Department of Human Anatomy, School of Basic Medical Sciences, \\ Guangxi Medical University, Nanning, Guangxi 530021; ${ }^{2}$ Department of Anatomy, \\ School of Basic Medical Sciences, Jinzhou Medical University, Jinzhou, Liaoning 121001, P.R. China
}

Received June 29, 2016; Accepted June 8, 2017

DOI: $10.3892 / \mathrm{mmr} .2017 .6850$

\begin{abstract}
Diabetic retinopathy (DR) is a common complication of diabetes mellitus (DM). We investigated whether Nogo receptor $(\mathrm{NgR})$ knockdown and ciliary neurotrophic factor (CNTF) treatment, either alone or in combination, ameliorated diabetic retinopathy (DR) in diabetic rat model. STZ-induced diabetic rats were administrated for a total of 12 weeks with $3 \mu \mathrm{M}$ siRNA (5 $\mu \mathrm{l})$ once every 6 weeks and/or $1 \mu \mathrm{g}$ CNTF weekly. The retinal tissues were excised. We measured cell number in ganglion cell layer (GCL) using H\&E staining and cell apoptosis using TUNEL assay. Bax, Bcl-2, Caspase-3, F-actin, GAP-43, NgR, RhoA and Rock1 levels were then analyzed by Western blotting, Immunohistochemistry or Real-time PCR. We found that NgR siRNA or CNTF injection alone significantly increased cell count in GCL in diabetic rats, inhibited ganglion cell apoptosis, elevated $\mathrm{Bcl}-2$, F-actin and GAP-43, and decreased Bax, Caspase-3, NgR, RhoA and Rock1 levels. Combination treatment further prevented retinal ganglion cell loss, enhanced growth cone cytoskeleton and axonal regeneration, and suppressed $\mathrm{NgR} / \mathrm{RhoA}$ /Rock1. Our results indicate that combination therapy has therapeutic potential for the treatment of DR.
\end{abstract}

\section{Introduction}

Diabetes mellitus (DM) is the most common metabolic disease worldwide (1). DM may become the seventh leading cause of human death by the year 2030 (2). The complications of DM include microvascular (retinopathy, nephropathy and neuropathy) and macrovascular complications (cardiovascular

Correspondence to: Dr Xuezheng Liu, Department of Human Anatomy, School of Basic Medical Sciences, Guangxi Medical University, 22 Shuangyong Road, Nanning, Guangxi 530021, P.R. China

E-mail: xuezheng_liu@sina.com

Key words: ciliary neurotrophic factor, combination therapy, diabetic retinopathy, NgR/RhoA/Rock1, siRNA disease) (3). Diabetic retinopathy (DR) is characterized by the increased vessel permeability and progressive vascular occlusion (4). DR is a main cause of visual impairment and blindness in adults (5). The pathogenesis of DR is multifactorial, such as hyperglycemia, advanced glycation end products, oxidative stress and inflammation (6,7).

Retinal ganglion cells (RGCs) are the final neurons in the retina that output vision signals to brain visual centers (8). The death of RGCs contributes to irreversible visual loss (9). Ciliary neurotrophic factor (CNTF) is a neurotrophic cytokine of the IL- 6 family and can induce neuron differentiation in the central nervous system (10). Mathews et al have reported that CNTF administration promotes RGC survival and provides neuroprotection against ischaemic optic nerve injury in animal models (11). Aizu et al have found that topical instillation of CNTF via eye drops protects STZ-induced diabetic rats from retinal degeneration (12).

RhoA is a GTPase protein that regulates cytoskeleton reorganization in stress fiber formation (13). RhoA exerts its downstream effect via effector proteins, Rho-associated protein kinase 1 (Rock1) and Rock2 (14). Lu et al have demonstrated that RhoA/Rock1 signaling is involved in the protection of microvascular endothelial cell dysfunction induced by hyperglycemia in an in vitro model of DR (15). Nogo receptor $(\mathrm{NgR})$ is a neural regeneration-associated membrane receptor for Nogo, oligodendrocyte-myelin glycoprotein and myelin-associated glycoprotein (16). Our previous study has demonstrated that NgR and Rock1 expression levels are elevated in the retina of diabetic rats. Downregulation of $\mathrm{NgR}$ inhibits retinal ganglion cell apoptosis and decreases Rock1 expression (17).

Our study focused on the effect of NgR inhibition and CNTF treatment on RGCs in DR in vivo. Furthermore, we evaluated the synergistic effect of combination therapy and the possible protective mechanisms. Our study provides a novel strategy for DR treatment.

\section{Materials and methods}

Animals and treatment. Male Sprague Dawley (SD) rats (weighting 200-250 g, purchased from Vital River, Beijing, 
China) were randomly assigned to 6 groups ( $n=24$ per group): i) Control group, ii) STZ group, iii) STZ+control siRNA group, iv) STZ+NgR siRNA group, v) STZ+CNTF group and vi) STZ+NgR siRNA+CNTF group. The rats in the STZ group were treated intraperitoneally with a single injection of $65 \mathrm{mg} / \mathrm{kg} \mathrm{STZ} \mathrm{(Solarbio,} \mathrm{Beijing,} \mathrm{China)} \mathrm{dissolved} \mathrm{in}$ $0.01 \mathrm{M}$ cold sodium citrate buffer and treated with saline. The control siRNA or NgR siRNA (5 $\mu \mathrm{l}$ and $3 \mu \mathrm{M})$ (GenePharma, Shanghai, China) were injected into the vitreous of diabetic rats in the STZ+control siRNA group or STZ+NgR siRNA group, respectively (This injection was repeated after 6 weeks). CNTF $(1 \mu \mathrm{g})$ (Sino Biological, Beijing, China) were administrated into the vitreous of diabetic rats in the STZ+CNTF group once a week for 12 weeks. The rats in the STZ+NgR siRNA+CNTF group received NgR siRNA and CNTF after induction of diabetes. The rats in the control group received sodium citrate buffer and saline. Blood glucose level (mM) was detected 3 days post-STZ administration for diabetes induction confirmation $(>16.7 \mathrm{mmol} / \mathrm{l})$. All the rats were sacrificed after 12 weeks. The retinal tissues were excised and fixed in $4 \%$ paraformaldehyde for further analyses. The experiments were performed in accordance with the Guide for the Care and Use of Laboratory Animals and approved by Animal Care and Use Committee of Guangxi Medical University (Nanning, China).

$H \& E$ staining. The paraffin-embedded retinal tissues were sectioned into $5-\mu \mathrm{m}$ slices. The sections were deparaffinized with xylene and graded ethanol (100, 95, 85 and 75\% ethanol). The sections were stained with hematoxylin for $5 \mathrm{~min}$ and incubated with $1 \%$ hydrochloric acid alcohol for $3 \mathrm{sec}$, followed by staining with eosin for $3 \mathrm{~min}$. Subsequently, the sections were dehydrated with graded ethanol $(75,85,95$, and $100 \%$ ethanol) and xylene. The sections were mounted with neutral gum and captured by OLYMPUS DP73 microscope (Olympus Corp., Tokyo, Japan).

TUNEL.The paraffin-embedded sections (5- $\mu \mathrm{m}$ thick) of retinal tissues were deparaffinized, treated with $0.1 \%$ Triton X-100 and blocked with $3 \% \mathrm{H}_{2} \mathrm{O}_{2}$. After washing with PBS, the sections were incubated with the mixture of terminal deoxynucleotidyl transferase (TdT) and fluorescein-labeled dUTP and then treated with converter-POD according to the manufacturer's protocol (Roche, Basel, Switzerland). DAB was added and the sections were counterstained with hematoxylin. Finally, the sections were dehydrated and photographed under OLYMPUS DP73 microscope.

Western blotting. The retinal tissues were lysed on the ice, followed by protein extraction. The protein concentration was determined by BCA assaykit (Wanleibio, Shenyang, China). The proteins were subjected to SDS-PAGE (8-13\%) and transferred to PVDF membranes. Then, membranes were blocked with non-fat milk dissolved in Tween-20/TBS buffer. Subsequently, the membranes were incubated with primary antibodies against NgR (1:10,000; ab184556; Abcam, Cambridge, UK), RhoA (1:200; sc-197; Santa Cruz Biotechnology, Inc., Dallas, TX, USA), Rock1 (1:200; sc-374388; Santa Cruz Biotechnology, Inc.), Bcl-2 (1:400; BA0412; Boster, Wuhan, China), Bax (1:400; BA0315; Boster), Caspase-3 (1:1000; ab2302; Abcam),
F-actin (1:500; ab205; Abcam), growth-associated protein-43 (GAP-43) (1:200; sc-33705; Santa Cruz Biotechnology, Inc.) at $4^{\circ} \mathrm{C}$ overnight and then with secondary antibody $(1: 5,000$; horseradish peroxidase-labeled IgG; WLA023 and WLA024; Wanleibio) for $45 \mathrm{~min}$ at $37^{\circ} \mathrm{C}$. The protein bands were visualized via ECL reagent and analyzed by Gel-Pro Analyzer (Media Cybernetics, Rockville, MD, USA).

Immunohistochemistry. Retinal tissue sections $(5-\mu \mathrm{m}$ thick) were deparaffinized with xylene and gradient ethanol (100, 95,85 and $75 \%$ ethanol). After antigen retrieval, the sections were treated with $\mathrm{H}_{2} \mathrm{O}_{2}$ and blocked with goat serum. Then, sections were incubated with primary antibodies against F-actin (1:200; bs-1571R; Bioss, Beijing, China) and GAP-43 (1:200; D163002; Sangon Biotech, Shanghai, China) at $4^{\circ} \mathrm{C}$ overnight and biotin-labeled secondary antibody (1:200; A0277; Beyotime Institute of Biotechnology, Haimen, China) at $37^{\circ} \mathrm{C}$ for $30 \mathrm{~min}$, followed by incubation with HRP-labeled avidin (A0303; Beyotime) at $37^{\circ} \mathrm{C}$ for $30 \mathrm{~min}$. The sections were visualized with $\mathrm{DAB}$, counterstained with hematoxylin and imaged under a microscope (Olympus Corp.).

Quantitative PCR ( $q P C R$ ). Total RNAs were extracted from the retinal tissues using RNApure Total RNA Extraction kit (BioTeke, Beijing, China) and reverse-transcribed to cDNAs using M-MLV Reverse Transcriptase (BioTeke). The volume of obtained cDNAs was $20 \mu \mathrm{l}$. qPCR analysis was carried out following the reaction conditions on Real-Time PCR system (BIONEER, Daejeon, Korea): $95^{\circ} \mathrm{C}$ for $10 \mathrm{~min}$, followed by 40 cycles of $95^{\circ} \mathrm{C}$ for $10 \mathrm{sec}, 60^{\circ} \mathrm{C}$ for $20 \mathrm{sec}$ and $72^{\circ} \mathrm{C}$ for $30 \mathrm{sec}$. The primers used were as follows: NgR forward, $5^{\prime}-\mathrm{GTCCCT}$ TCCAGACCAATCAGC-3' and reverse, 5'-GCCATTGCC TGGTGGAGTGT-3'; RhoA forward, 5'-TCGGAATGATGA GCACACAA-3' and reverse, 5'-GCTTCACAAGATGAGGCA C-3'; Rock1 forward, 5'-GTGATGGCTATTATGGACG-3' and reverse, 5'-AGGAAGGCACAAATGAGAT-3'; F-actin forward, 5'-GAAGAGAAAGCAGCAGTGTTA-3' and reverse, 5'-GGAGCCAGAGGGTGGTTAT-3'; GAP-43 forward, 5'-AGGGAGATGGCTCTGCTAC-3' and reverse, 5'-CAC ATCGGCTTGTTTAGGC-3'; GAPDH forward, 5'-CGGCAA GTTCAACGGCACAG-3' and reverse, 5'-CGCCAGTAGACT CCACGACAT-3'. The primers were synthesized by Sangon Biotech. Gene expression was normalized to GAPDH and calculated using the $2^{-\Delta \Delta C q}$ formula.

Statistical analysis. Data are expressed as the mean \pm SD and analyzed by Student's t-test for the comparison of every two groups. $\mathrm{P}<0.05$ was considered to indicate a statistically significant difference.

\section{Results}

Effect of NgR siRNA and CNTF injection on the number of cells in GCL in diabetic rats. Histopathological examination showed that the cell numbers in GCL (Fig. 1) were decreased in diabetic rats compared with those in non-diabetic control rats. We found that NgR siRNA or CNTF injection alone increased the number of cells in GCL. Similarly, combination treatment further enhanced the ability of single treatment, although the difference was not statistically significant. 


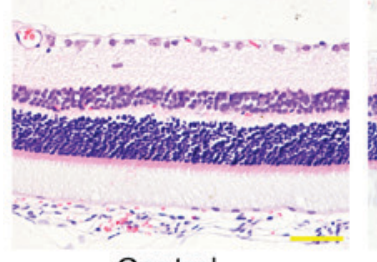

Control

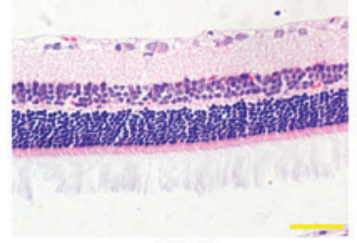

$\mathrm{STZ}$

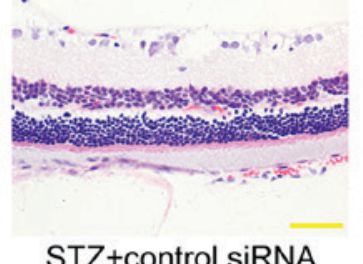

STZ+control siRNA

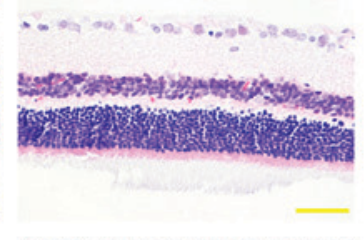

Figure 1. Effect of NgR siRNA and/or CNTF injection on the cell number in GCL in vivo. Diabetes was induced by STZ injection (65 mg/kg) in male SD rats. The diabetic rats were administrated with siRNA and/or CNTF. After animal experiments, the retina was excised from the sacrificed rats and subjected to H\&E staining. Scale bars $50 \mu \mathrm{m}$. Number of cells in GCL was measured. ${ }^{* *} \mathrm{P}<0.01$ vs. STZ group. ${ }^{\& \&} \mathrm{P}<0.01 \mathrm{vs}$. STZ+control siRNA group.

A

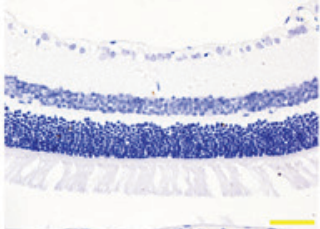

Control

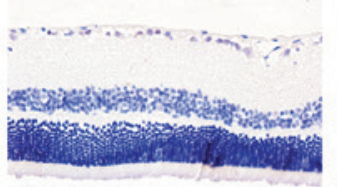

$\mathrm{STZ}+\mathrm{NgR}$ siRNA

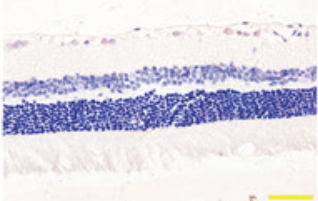

STZ

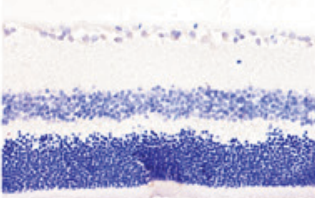

STZ+CNTF

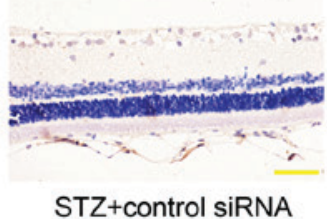

STZ+control siRNA

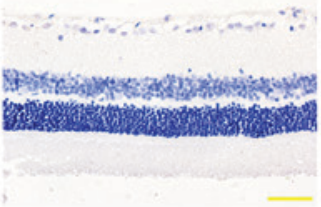

$\mathrm{STZ}+\mathrm{CNTF}+\mathrm{NgR}$ siRNA

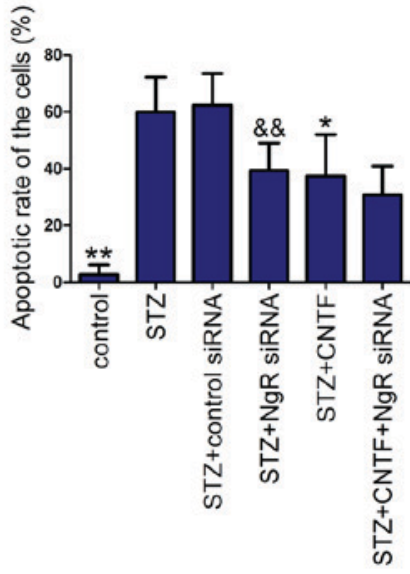

B
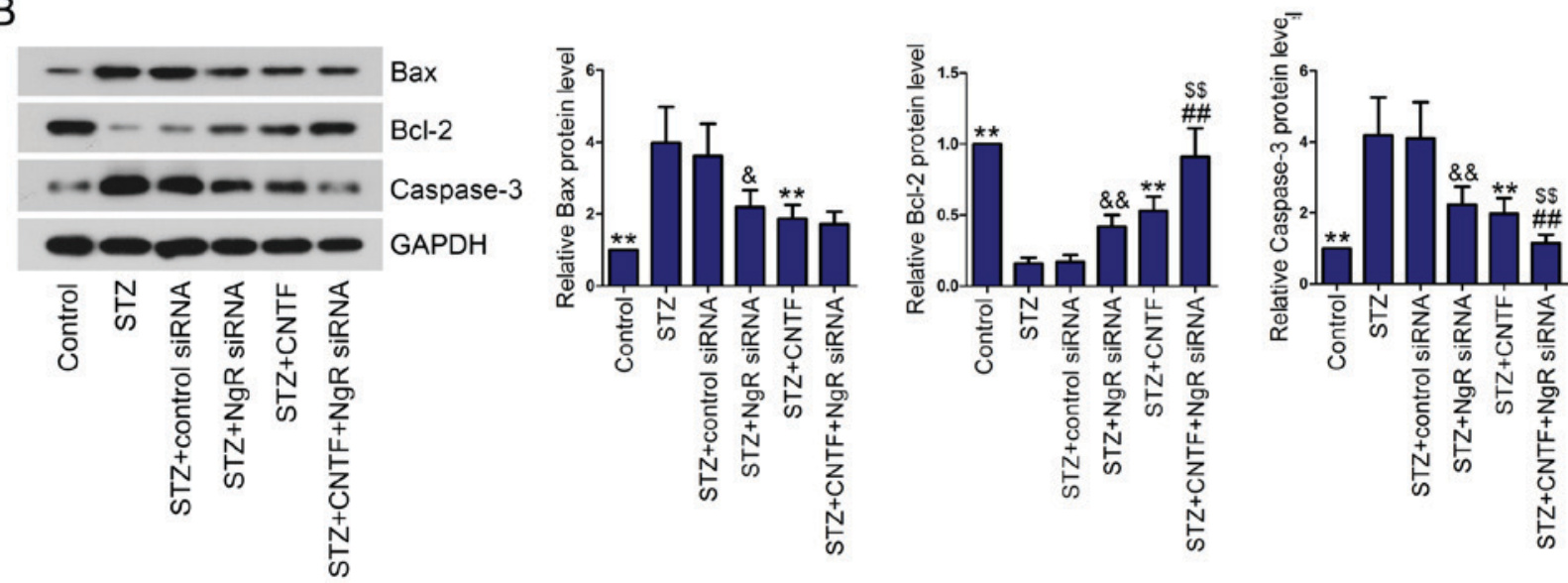

Figure 2. Effect of NgR siRNA and/or CNTF injection on cell apoptosis in the retina in vivo. (A) Apoptosis was detected by TUNEL assay. Scale bars $50 \mu \mathrm{m}$. (B) Bcl-2, Bax and Caspase-3 protein levels were examined by western blotting. ${ }^{*} \mathrm{P}<0.05$ and ${ }^{* *} \mathrm{P}<0.01$ vs. STZ group. ${ }^{\text {\& }} \mathrm{P}<0.05$ and ${ }^{\text {\&\&}} \mathrm{P}<0.01$ vs. $\mathrm{STZ}+\mathrm{control}$ siRNA group. ${ }^{\$ \$} \mathrm{P}<0.01$ vs. $\mathrm{STZ}+\mathrm{NgR}$ siRNA group. ${ }^{\# \#} \mathrm{P}<0.01$ vs. $\mathrm{STZ}+\mathrm{CNTF}$ group.

Effect of NgR siRNA and CNTF injection on cell apoptosis in the retinal tissues of diabetic rats. Death of RGCs is one of the earliest events in DR occurrence and progression (18). Therefore, we evaluated cell apoptosis using TUNEL assay. As expected, diabetic rats presented higher apoptosis rate of the cells in the retina than control rats (Fig. 2A). However, NgR knockdown or CNTF incubation significantly protected RGCs against apoptosis in diabetic rats. Combined injection of $\mathrm{NgR}$ siRNA and 
A

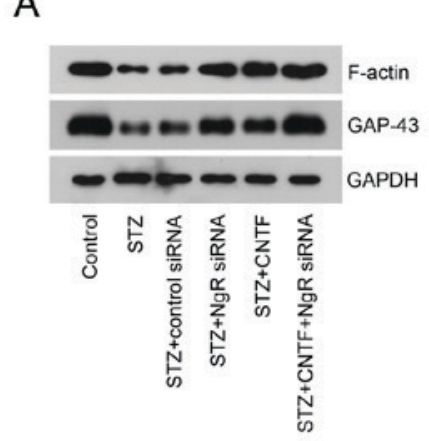

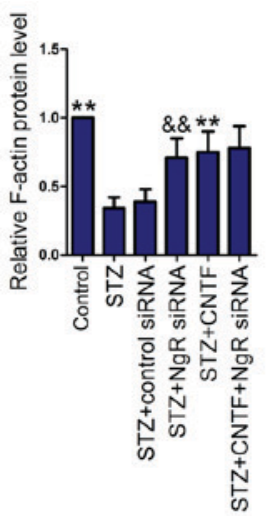

C

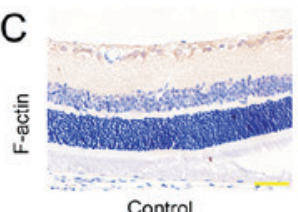

Control

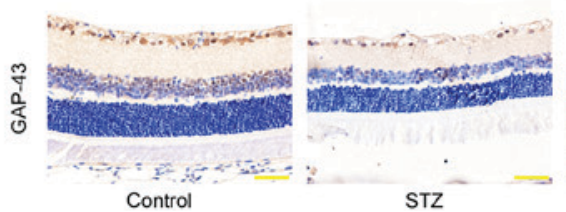

F-actin

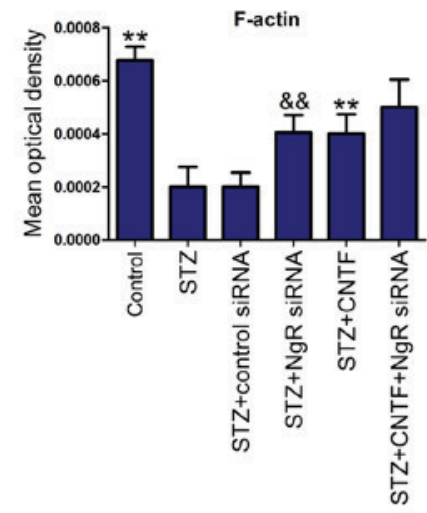

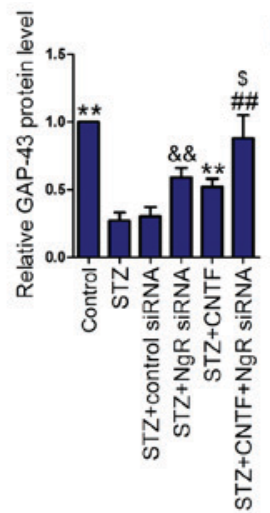

B
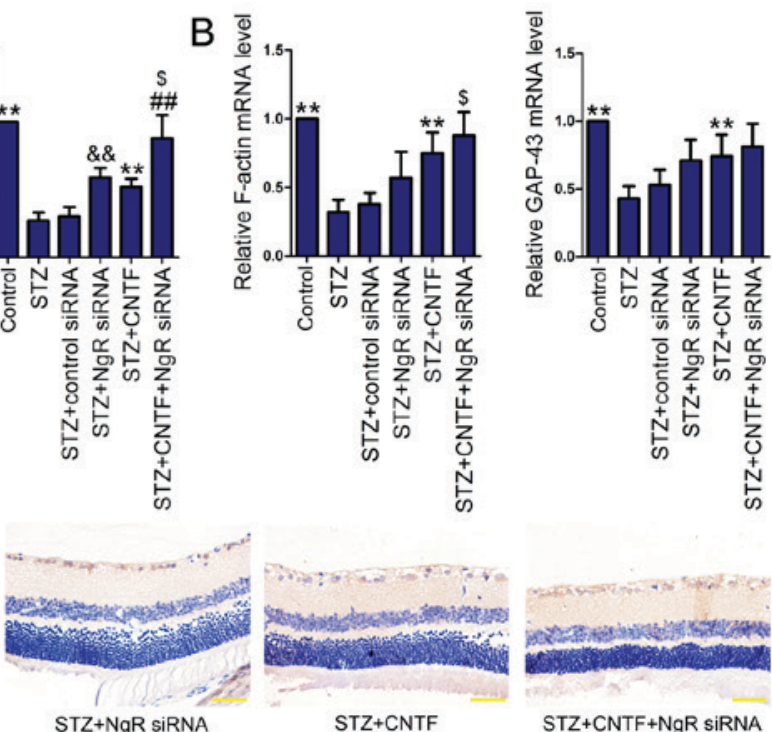

STZ+control siRNA

STZ+NgR siRNA
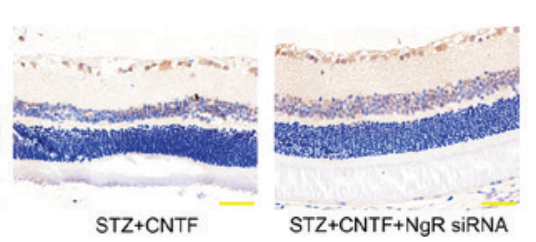

STZ+control siRNA

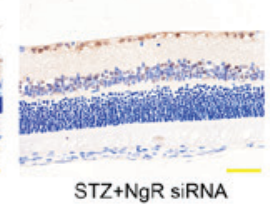

$\mathrm{STZ}+\mathrm{CNTF}$

$\mathrm{STZ}+\mathrm{CNTF}+\mathrm{NgR}$ siRNA

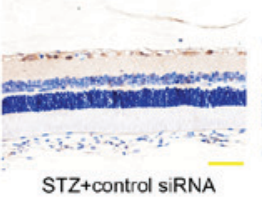

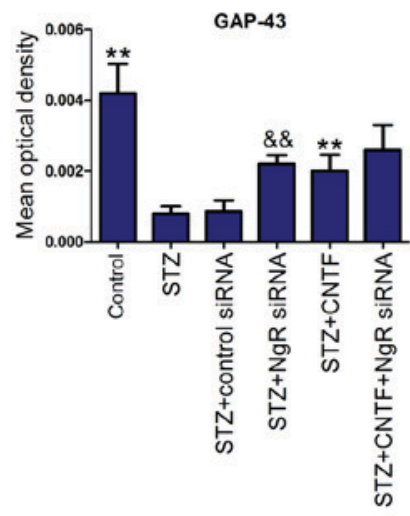

Figure 3. Effect of NgR siRNA and/or CNTF injection on F-actin and GAP-43 in vivo. (A) Western blot analysis of F-actin and GAP-43. (B) qPCR analysis of F-actin and GAP-43. (C) F-actin and GAP-43 were examined by IHC. Scale bars $50 \mu \mathrm{m}$. ${ }^{* *} \mathrm{P}<0.01$ vs. STZ group. \&\&P<0.01 vs. STZ+control siRNA group. ${ }^{\$} \mathrm{P}<0.05$ vs. STZ+NgR siRNA group. ${ }^{\# \#} \mathrm{P}<0.01$ vs. STZ+CNTF group.

CNTF decreased the apoptotic rate of RGCs in diabetic rats in comparison with the STZ+NgR siRNA group or STZ+CNTF group, however, no significant difference was observed between the single treatment group and the combination group. Next, we measured the levels of apoptosis-related proteins (Bax, Bcl-2 and Caspase-3) in the retinal tissues using western blotting. We demonstrated that Bax and Caspase-3 levels were significantly upregulated in the retinal tissues of diabetic rats compared with control rats, whereas anti-apoptotic protein Bcl-2 was downregulated (Fig. 2B). NgR siRNA alone and CNTF injection alone notably reversed diabetes-induced cell apoptosis by decreasing Bax and Caspase-3 levels and increasing Bcl-2 level. Compared with the STZ+NgR siRNA group or STZ+CNTF group, NgR siRNA injection combined with CNTF further enhanced the anti-apoptotic effect of NgR knockdown and CNTF.

Effect of NgR siRNA and CNTF injection on growth cone cytoskeleton and axonal regeneration. To evaluate the effect of NgR knockdown and CNTF treatment, either alone or in combination, on growth cone cytoskeleton and axonal regeneration, we measured the expression levels of F-actin and GAP-43 in the retinal tissues. We observed the downregulated expression of F-actin and GAP-43 at both protein (Fig. 3A) and mRNA levels (Fig. 3B) in the retinal tissues of diabetic rats. However, NgR siRNA or CNTF incubation significantly elevated the levels of these two proteins. Moreover, the combination of NgR siRNA and CNTF further increased F-actin and GAP-43 levels. We then performed IHC analysis (Fig. 3C) and verified the results obtained from western blotting and qPCR.

Effect of $N g R$ siRNA and CNTF injection on $N g R / R h o A / R o c k 1$ signaling pathway. We then examined the effect of $\mathrm{NgR}$ knockdown and CNTF treatment, either alone or in combination, on the activation of $\mathrm{NgR} / \mathrm{RhoA} / \mathrm{Rock} 1$ signaling pathway in diabetic rats. The results showed that $\mathrm{NgR}$, RhoA and Rock1 levels were elevated in diabetic rats in comparison with 
A

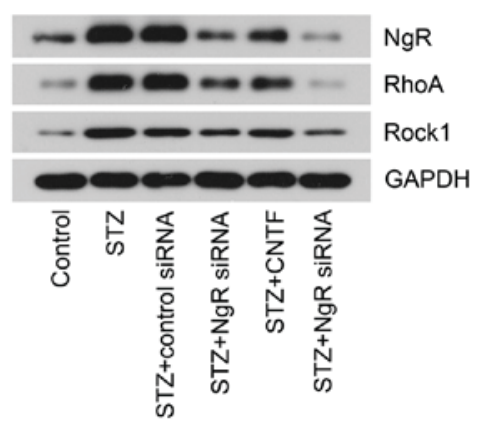

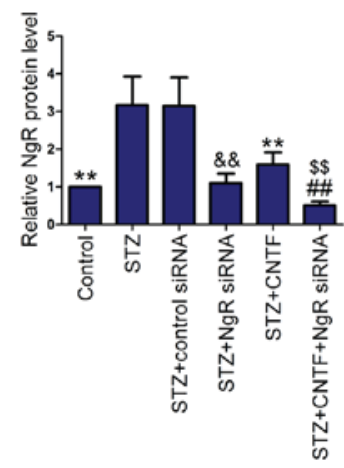
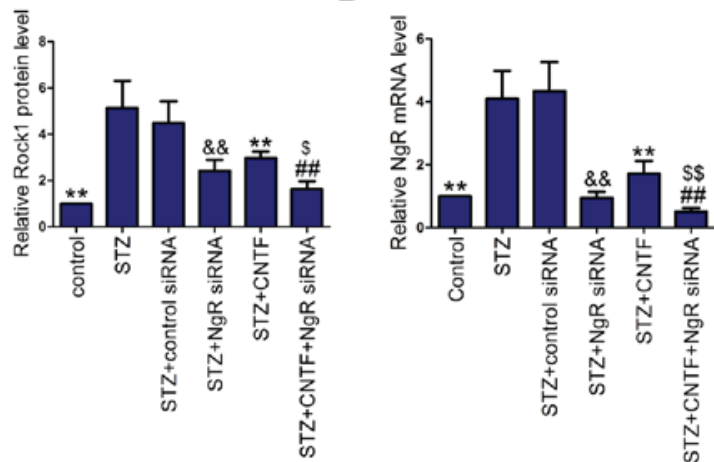
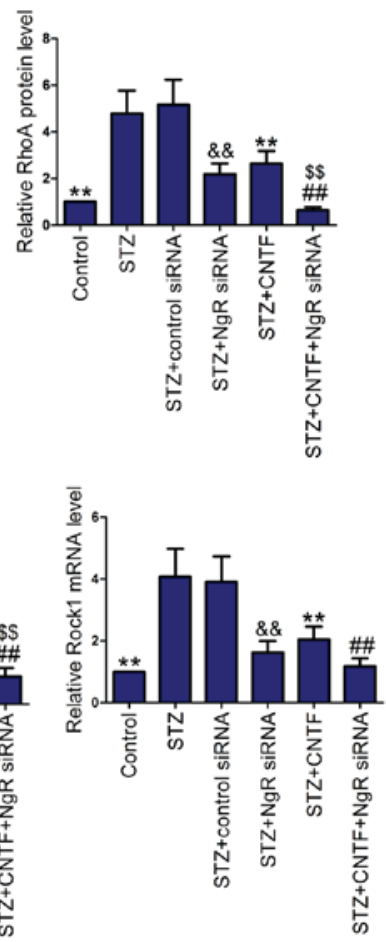

Figure 4. Effect of NgR siRNA and/or CNTF injection on NgR/RhoA/Rock1 signaling pathway in vivo. (A) NgR, RhoA and Rock1 levels were measured by western blotting. (B) NgR, RhoA and Rock1 levels were measured by qPCR. ${ }^{* *} \mathrm{P}<0.01$ vs. STZ group. \&\&P $<0.01$ vs. STZ+control siRNA group. ${ }^{\$} \mathrm{P}<0.05$ and ${ }^{\$} \mathrm{P}<0.01$ vs. STZ+NgR siRNA group. ${ }^{\#} \mathrm{P}<0.01$ vs. $\mathrm{STZ}+\mathrm{CNTF}$ group.

control rats, as demonstrated by western blotting (Fig. 4A) and qPCR (Fig. 4B). After injection with NgR siRNA or CNTF, the diabetic rats expressed lower levels of $\mathrm{NgR}, \mathrm{RhoA}$ and Rock1 in the retinal tissues than the corresponding model rats. As expected, the expression of $\mathrm{NgR}$, RhoA and Rock1 were significantly inhibited by the combined administration of $\mathrm{NgR}$ siRNA and CNTF compared with the single treatment group.

\section{Discussion}

Understanding the pathological mechanisms of DR and targeting them are essential to DR prevention. In our study, we aimed to investigate the effect of $\mathrm{NgR} / \mathrm{RhoA} / \mathrm{Rock} 1$ signaling pathway inhibition and/or CNTF treatment on retinal ganglion cells in diabetic rats.

RGCs are the main part of nervous tissues in the retina and they relay visual signals to the brain (19). Apoptosis of RGCs plays an essential role in onset and progression of DR (20). Tong et al have demonstrated that $\mathrm{NgR}$ silencing inhibits C6 cell proliferation and promotes cell apoptosis (21). Wang et al have reported that CNTF protects neuroblastoma SH-SY5Y cells from cytotoxicity and apoptosis induced by amyloid beta peptide $\left(\mathrm{A} \beta_{1-42}\right)$ (22). However, the effect of NgR knockdown or CNTF treatment and their synergistic effect on RGC-5 cells needed to be clarified. In our study, a rat model of DM was induced by a single injection of STZ $(65 \mathrm{mg} / \mathrm{kg})$. After administration of siRNAs or CNTF, the retinal tissues were excised and subjected to H\&E staining to measure RGC count. The results showed that NgR siRNA or CNTF injection, as well as combined therapy, prevented diabetes-induced the loss of ganglion cells in GCL. B-cell-lymphoma 2 (Bcl-2) protein family members regulate cell apoptosis and this family consists of proapoptotic proteins (Bax and Bad) and antiapoptotic (Bcl-2 and $\mathrm{Bcl}-\mathrm{xL}$ ) (23). Bax is a soluble protein that usually exists in the cytosol. Bax translocates to mitochondrial membranes, enhances membrane permeabilization, results in cytochrome c release and thus induces apoptosis (24). However, Bcl-2 can inhibit the translocation of Bax in the cells undergo apoptosis (25). Apoptosis is the result of caspase cascades. Caspase-3 is the downstream executor of these cascades (26). The results showed that, consistent with previous study (27), diabetes induced RGC apoptosis in the retinal tissues, along with the increases of Bax and Caspase- 3 and the decrease of Bcl-2. NgR siRNA or CNTF injection, as well as combined therapy, protected cells from diabetes-induced apoptosis by downregulating Bax and Caspase-3 and upregulating Bcl-2. Our results suggested that both single agent treatment and combination treatment alleviated diabetes-induced apoptosis by regulating the expression of apoptosis-related proteins in diabetic rats.

F-actin is a main element of cytoskeleton and functions in cell shape, motility and division (28). F-actin dynamics plays an important role in regulating axon extension (29). GAP-43, which belongs to the calmodulin-binding protein family, is a protein kinase $\mathrm{C}$ (PKC) substrate and is highly expressed in adult RGCs $(30,31)$. Increased expression of GAP-43 correlates with cytoskeletal organization in nerve ending, neurite outgrowth and axon regeneration (32). Liu et al have found that CNTF attenuates gp120-induced inhibition of neurite outgrowth by elevating GAP-43 expression in dorsal root ganglion (DRG) explants (33). Our results showed that diabetes resulted in the loss of F-actin and GAP-43 in the retina. NgR siRNA, CNTF or combination injection prevented diabetes-induced loss of F-actin and GAP-43. Our results 
suggested that NgR siRNA, CNTF or combination injection may promote growth cone cytoskeleton and axonal regeneration by regulating F-actin and GAP-43.

RhoA, a small GTPase protein, is associated with the contractility of actin cytoskeleton (13). Moreover, RhoA has been demonstrated to be involved in cell proliferation, apoptosis and metastasis (34). Rock1 is a downstream target of RhoA (35).Peng et al have reported that RhoA/ROCK1 pathway is inhibited by simvastatin in the treatment of early-stage of diabetic nephropathy (DN) (36). Additionally, RhoA/ROCK1 pathway has been shown to be involved in the pathology of DR via triggering microvascular endothelial dysfunction (15). In our study, we demonstrated that NgR siRNA, CNTF or combination injection inhibited the activation of $\mathrm{NgR} / \mathrm{RhoA} /$ Rock1 signaling pathway induced by diabetes.

In conclusion, the combination of $\mathrm{NgR}$ knockdown and CNTF treatment exhibits obvious advantages over either therapy alone. The combined therapy may be a potential therapeutic strategy for the treatment of DR.

\section{Acknowledgements}

This study was supported by a grant from the National Natural Science Foundation of China (grant no. 81571383).

\section{References}

1. Kawser Hossain M, Abdal Dayem A, Han J, Kumar Saha S, Yang GM, Choi HY and Cho SG: Recent advances in disease modeling and drug discovery for diabetes mellitus using induced pluripotent stem cells. Int J Mol Sci 17: 256, 2016.

2. Roifman I, Ghugre N, Zia MI, Farkouh ME, Zavodni A, Wright GA and Connelly KA: Diabetes is an independent predictor of right ventricular dysfunction post ST-elevation myocardial infarction. Cardiovasc Diabetol 15: 34, 2016.

3. Amutha A and Mohan V: Diabetes complications in childhood and adolescent onset type 2 diabetes-a review. J Diabetes Complications 30: 951-957, 2016.

4. van den Born JC, Hammes HP, Greffrath W, van Goor H and Hillebrands JL; DFG GRK International Research Training Group 1874 Diabetic Microvascular Complications (DIAMICOM): Gasotransmitters in vascular complications of diabetes. Diabetes 65: 331-345, 2016.

5. Kur J, Burian MA and Newman EA: Light adaptation does not prevent early retinal abnormalities in diabetic rats. Sci Rep 6 : 21075, 2016.

6. Liu S, Lin YU and Liu X: Protective effects of SIRT1 in patients with proliferative diabetic retinopathy via the inhibition of IL-17 expression. Exp Ther Med 11: 257-262, 2016.

7. He K, Lv W, Zhang Q, Wang Y, Tao L and Liu D: Gene set enrichment analysis of pathways and transcription factors associated with diabetic retinopathy using a microarray dataset. Int J Mol Med 36: 103-112, 2015.

8. Nashine S, Liu Y, Kim BJ, Clark AF and Pang IH: Role of C/EBP homologous protein in retinal ganglion cell death after ischemia/reperfusion injury. Invest Ophthalmol Vis Sci 56: 221-231, 2014.

9. Wang W, Chan A, Qin Y, Kwong JM, Caprioli J, Levinson R, Chen L and Gordon LK: Programmed cell death- 1 is expressed in large retinal ganglion cells and is upregulated after optic nerve crush. Exp Eye Res 140: 1-9, 2015.

10. Seidel JL, Faideau M, Aiba I, Pannasch U, Escartin C, Rouach N, Bonvento G and Shuttleworth CW: Ciliary neurotrophic factor (CNTF) activation of astrocytes decreases spreading depolarization susceptibility and increases potassium clearance. Glia 63 : 91-103, 2015

11. Mathews MK, Guo Y, Langenberg $\mathrm{P}$ and Bernstein SL: Ciliary neurotrophic factor (CNTF)-mediated ganglion cell survival in a rodent model of non-arteritic anterior ischaemic optic neuropathy (NAION). Br J Ophthalmol 99: 133-137, 2015.
12. Aizu Y, Katayama H, Takahama S, Hu J, Nakagawa $H$ and Oyanagi K: Topical instillation of ciliary neurotrophic factor inhibits retinal degeneration in streptozotocin-induced diabetic rats. Neuroreport 14: 2067-2071, 2003.

13. Wang Y, Wang D and Guo D: MiR-124 promote neurogenic transdifferentiation of adipose derived mesenchymal stromal cells partly through RhoA/ROCK1, but Not ROCK2 signaling pathway. PLoS One 11: e0146646, 2016.

14. Rigassi L, Barchiesi Bozzolo F, Lucchinetti E, Zaugg M, Fingerle J, Rosselli M, Imthurn B, Jackson EK and Dubey RK: 2-Methoxyestradiol blocks the RhoA/ROCK1 pathway in human aortic smooth muscle cells. Am J Physiol Endocrinol Metab 309: E995-E1007, 2015.

15. Lu QY, Chen W, Lu L, Zheng Z and Xu X: Involvement of RhoA/ROCK1 signaling pathway in hyperglycemia-induced microvascular endothelial dysfunction in diabetic retinopathy. Int J Clin Exp Pathol 7: 7268-7277, 2014.

16. Cao Y, Dong YX, Xu J, Chu GL, Yang ZH and Liu YM: Spatiotemporal expression of Nogo-66 receptor after focal cerebral ischemia. Neural Regen Res 11: 132-136, 2016.

17. Liu X, Zuo Z, Liu W, Wang Z, Hou Y, Fu Y and Han Y: Upregulation of Nogo receptor expression induces apoptosis of retinal ganglion cells in diabetic rats. Neural Regen Res 9: 815-820, 2014.

18. Martin PM, Roon P, Van Ells TK, Ganapathy V and Smith SB: Death of retinal neurons in streptozotocin-induced diabetic mice. Invest Ophthalmol Vis Sci 45: 3330-3336, 2004.

19. Galan A, Dergham P, Escoll P, de-la-Hera A, D'Onofrio PM, Magharious MM, Koeberle PD, Frade JM and Saragovi HU: Neuronal injury external to the retina rapidly activates retinal glia, followed by elevation of markers for cell cycle re-entry and death in retinal ganglion cells. PLoS One 9: e101349, 2014.

20. Wang DD, Zhu HZ, Li SW, Yang JM, Xiao Y, Kang QR, Li CY, Zhao Y, Zeng Y, Li Y, et al: Crude saponins of Panax notoginseng have neuroprotective effects to inhibit palmitate-triggered endoplasmic reticulum stress-associated apoptosis and loss of postsynaptic proteins in staurosporine differentiated RGC-5 retinal ganglion cells. J Agric Food Chem 64: 1528-1539, 2016.

21. Tong $\mathrm{S}$, Xiong $\mathrm{N}$ and Shen J: RNA interference suppression of Nogo-66 receptor prevents Nogo-66-mediated inhibition of invasion and adhesion and simultaneously increases cell apoptosis in C6 cells. Oncol Rep 30: 2171-2178, 2013.

22. Wang K, Xie M, Zhu L, Zhu X, Zhang K and Zhou F: Ciliary neurotrophic factor protects SH-SY5Y neuroblastoma cells against A $\beta 1-42$-induced neurotoxicity via activating the JAK2/STAT3 axis. Folia Neuropathol 53: 226-235, 2015.

23. Cheng $\mathrm{CH}$, Cheng YP, Chang IL, Chen HY, Wu CC and Hsieh CP: Dodecyl gallate induces apoptosis by upregulating the caspase-dependent apoptotic pathway and inhibiting the expression of anti-apoptotic Bcl-2 family proteins in human osteosarcoma cells. Mol Med Rep 13: 1495-1500, 2016.

24. Jia HM, Li Q, Zhou C, Yu M, Yang Y, Zhang HW, Ding G, Shang $\mathrm{H}$ and Zou ZM: Chronic unpredictive mild stress leads to altered hepatic metabolic profile and gene expression. Sci Rep 6: 23441, 2016.

25. Zhang H, Xiong Z, Wang J, Zhang S, Lei L, Yang L and Zhang Z: Glucagonlike peptide1 protects cardiomyocytes from advanced oxidation protein productinduced apoptosis via the PI3K/Akt/Bad signaling pathway. Mol Med Rep 13: 1593-1601, 2016.

26. Zhang X, Jiang D, Jiang W, Zhao $M$ and Gan J: Role of TLR4-Mediated PI3K/AKT/GSK-3 $\beta$ signaling pathway in apoptosis of rat hepatocytes. Biomed Res Int 2015: 631326, 2015.

27. Foureaux G, Nogueira BS, Coutinho DC, Raizada MK, Nogueira JC and Ferreira AJ: Activation of endogenous angiotensin converting enzyme 2 prevents early injuries induced by hyperglycemia in rat retina. Braz J Med Biol Res 48: 1109-1114, 2015.

28. Yamazaki S, Yamamoto K, de Lanerolle P and Harata M: Nuclear F-actin enhances the transcriptional activity of $\beta$-catenin by increasing its nuclear localization and binding to chromatin. Histochem Cell Biol 145: 389-399, 2016.

29. Atkinson-Leadbeater K, Hehr CL, Johnston J, Bertolesi G and McFarlane S: EGCG stabilizes growth cone filopodia and impairs retinal ganglion cell axon guidance. Dev Dyn 245: 667-677, 2016.

30. Zhu Q, Liu Z, Wang C, Nie L, He Y, Zhang Y, Liu X and Su G: Lentiviral-mediated growth-associated protein-43 modification of bone marrow mesenchymal stem cells improves traumatic optic neuropathy in rats. Mol Med Rep 12: 5691-5700, 2015. 
31. Ivanov D, Dvoriantchikova G, Nathanson L, McKinnon SJ and Shestopalov VI: Microarray analysis of gene expression in adult retinal ganglion cells. FEBS Lett 580: 331-335, 2006.

32. Benowitz LI and Routtenberg A: GAP-43: An intrinsic determinant of neuronal development and plasticity. Trends Neurosci 20: 84-91, 1997.

33. Liu H, Liu G and Bi Y: CNTF regulates neurite outgrowth and neuronal migration through JAK2/STAT3 and PI3K/Akt signaling pathways of DRG explants with gp120-induced neurotoxicity in vitro. Neurosci Lett 569: 110-115, 2014.

34. Huang Y, Chen JB, Yang B, Shen H, Liang JJ and Luo Q RhoA/ROCK pathway regulates hypoxia-induced myocardial cell apoptosis. Asian Pac J Trop Med 7: 884-888, 2014.
35. Chang J, Xie M, Shah VR, Schneider MD, Entman ML, Wei L and Schwartz RJ: Activation of Rho-associated coiled-coil protein kinase 1 (ROCK-1) by caspase-3 cleavage plays an essential role in cardiac myocyte apoptosis. Proc Natl Acad Sci USA 103: 14495-14500, 2006.

36. Peng H, Luo P, Li Y, Wang C, Liu X, Ye Z, Li C and Lou T: Simvastatin alleviates hyperpermeability of glomerular endothelial cells in early-stage diabetic nephropathy by inhibition of RhoA/ROCK1. PLoS One 8: e80009, 2013. 